\title{
Slow-growing lung cancer as an emerging entity: from screening to clinical management
}

\author{
Maurizio Infante1, Thierry Berghmans², Marjolein A. Heuvelmans ${ }^{3}$, \\ Gunnar Hillerdal ${ }^{4}$ and Matthijs Oudkerk ${ }^{3}$
}

Affiliations: ${ }^{1}$ Dept of Thoracic Surgery, IRCCS Istituto Clinico Humanitas, Milan, Italy. ${ }^{2}$ Oncology Thoracic Unit and Dept of Intensive Care Institut Jules Bordet, Brussels, Belgium. ${ }^{3}$ Center for Medical Imaging - North East Netherlands, Dept of Radiology, University of Groningen, University Medical Center Groningen, Groningen, The Netherlands. ${ }^{4}$ Dept of Lung Medicine and Allergy, Karolinska Hospital, Stockholm, Sweden.

Correspondence: M. Infante, Dept of Thoracic Surgery, IRCCS Istituto Clinico Humanitas, Via Manzoni 56 , 20089 Rozzano Milan, Italy. E-mail: maurizio.infantedcancercenter.humanitas.it

ABSTRACT The current paradigm is that untreated lung cancer is invariably and rapidly fatal, therefore the medical community normally dismisses the idea that a patient could live with such a disease for years without any therapy.

Yet evidence from lung cancer screening research and from recent clinical series suggests that, although rarely recognised in routine practice, slow-growing lung cancers do exist and are more common than previously thought.

Here, current evidence is reviewed and clinical cases are illustrated to show that slow-growing lung cancer is a real clinical entity, and the reasons why management protocols developed in the screening setting may also be useful in clinical practice are discussed. Features suggesting that a lung cancer may be slow-growing are described and appraised, areas of uncertainty are examined, modern management options for earlystage disease are evaluated and the influence that all this knowledge might have on our clinical decisionmaking is weighed. Further research directed at developing appropriate guidelines for these peculiar but increasingly common patients is warranted.

@ERSpublications

The increasingly common incidence of slow-growing lung cancer and its influence on clinical decision-making is discussed http://ow.ly/oZ6c2

For editorial comments see page 1459 .

Received: Nov 162012 | Accepted after revision: April 222013 | First published online: May 162013

Conflict of interest: None declared.

Copyright @ERS 2013 


\section{Introduction}

The prognosis for patients with untreated lung cancer has always been grim, with a median survival time of only 10-14 months, even for early-stage disease [1-3], and their lives are considered to be at immediate risk unless effective treatment is instituted without delay. Yet in 1984, a longitudinal study on 20000 atomic bomb survivors who received biannual screening chest radiographs over 20 years already suggested that some patients could harbour slow-growing pulmonary tumours [4].

Later, indirect evidence derived from early randomised controlled trials of lung cancer screening with chest radiography also hinted that slow lung cancers, so slow that they would not cause harm or symptoms within the patient's lifetime even if left untreated (thereby termed indolent), might indeed exist, and even be fairly common. In these studies, significantly more lung cancers were actually detected with screening and treated at an early stage, but with a similar number of lung cancer deaths compared with the nonscreened group, which suggested overdiagnosis of indolent disease [5-7].

According to the exponential cancer growth model [8], a 1-cm tumour with a volume doubling time (VDT) of 36 days would require only 180 days (i.e. five doublings) to reach $3 \mathrm{~cm}$ in size, and only 360 days (10 doublings) to become a $10-\mathrm{cm}$ mass, at which time considerable symptoms and death are expected to occur. With a VDT of 365 days, the theoretical survival time from detection of a 1-cm tumour to death would be 3650 days: 10 years, even without therapy.

However, these are most often regarded as mere theoretical assumptions. In fact, the medical community normally dismisses the idea that some patients with lung cancer might live with their disease for years without treatment. But does slow-growing lung cancer really exist? And if so, how frequent is it?

\section{Evidence supporting the existence of slow-growing lung cancer}

In several early detection studies and in recent clinical series, patients with undetermined lung nodules that were eventually diagnosed as lung cancers have been intentionally followed for a number of reasons, and growing nodules have been retrospectively identified in prior scans, thus allowing calculation of their volume doubling times. These studies have been summarised in table 1.

Lung cancers detected by standard chest radiographs had short VDTs (i.e. shorter than the chosen cut-off) in $>90 \%$ of the cases, but small lung cancers detected using computerised tomography (CT) had long VDTs in $23-51 \%$ of assessed cases, with the exception of the International Early Lung Cancer Action Program (I-ELCAP) series, where the figure was only $3 \%$ [16].

The cut-off for slow-growing lung cancer varied, but most authors utilised the 400-day limit proposed by YANKELEVITZ et al. [9]. Therefore, we eventually estimated the percentage of cases in each study that had a VDT of $\geqslant 400$ days by taking into account the number of lung cancer cases with such a long VDT in each study. When a different cut-off was used, the data were extrapolated if possible. If not, the number of patients whose cancer did not grow at all was conservatively utilised for two studies [10, 11], or omitted. We then divided that number by the overall number of patients included in each study, assuming that all cases that did not have a VDT assessment would be fast-growing.

The lowest percentages were reported by YANKelevitz et al. [9] for the Mayo Lung Project and Memorial Sloan-Kettering populations, and by HENSCHKE et al. [16] for the I-ELCAP patients. In contrast, some Japanese clinical studies reported very high rates of slow-growing lung cancer [13-15].

The results of these studies should be interpreted with caution, as the percentage of cancers that did have a VDT assessment in these patient populations is often not reported in retrospective studies, and varies widely even in prospective trials. For example, VDT data is not reported for 405 baseline cancers in the I-ELCAP study [19]. Taking these into account, only 111 (22\%) out of 516 cases had a VDT assessment in that population. It is therefore difficult to estimate the real magnitude of this phenomenon.

Nevertheless, it is apparent that, although still rarely recognised in clinical practice, slow-growing lung cancer is a real clinical entity and more common than previously thought.

Therefore, in theory, our management strategies for lung cancer patients in the current era might be modulated to some extent according to this new evidence.

As usual, the first steps should be to ascertain whether the true nature of the nodule or lesion we are dealing with is benign or cancerous, and if cancer is confirmed, to assess the patient's underlying condition thoroughly.

Ideally, we might also try to estimate whether it is more probably a fast, aggressive lung cancer or a slowgrowing tumour; and eventually discuss the risks and benefits of all possible management strategies in the light of all the above elements. 


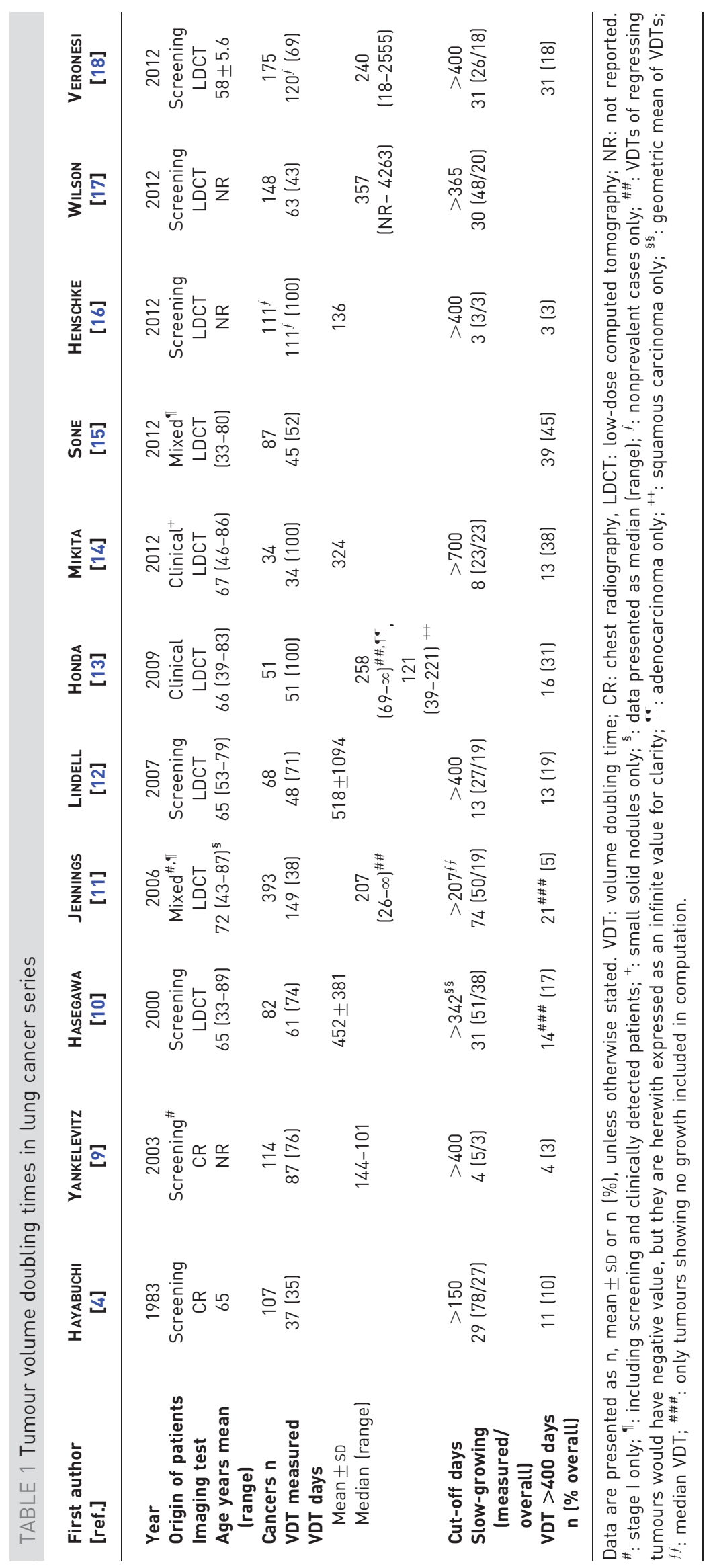




\section{Differentiating small lung cancers from benign lesions}

In some screening programmes, the prevalence of subjects with undetermined nodules may exceed $50 \%$ and the formidable number of undetermined nodules detected by CT, few of which are true early tumours, represents a major challenge.

Specific protocols had to be devised in order to avoid unnecessary patient anxiety, costs and morbidity related to the assessment of so many potentially dangerous, but ultimately harmless, nodules detected by CT, while preserving a high sensitivity for early lung cancer.

The probability of malignancy in an undetermined pulmonary nodule depends on its size, its features on $\mathrm{CT}$, and individual risk factors [20]; it is lowest for sub-centimetre solid nodules $(<1-7 \%)$ and highest for focal ground-glass lesions (59-73\%) [21, 22].

Although often suggestive, morphology alone is frequently misleading, while both size and nodule growth rate are strong predictors for malignancy [12, 23-25]; therefore modern diagnostic work-up protocols for screening-detected pulmonary lesions are mainly based on size at detection and on follow-up CT scans at set intervals, with two-dimensional (2D) or three-dimensional (3D) growth assessments.

The NELSON group was the first and only group that consistently used 3D assessments and VDT measurements alone for solid nodule evaluation (fig. 1) in their early detection study [26].

Nodules with a volume $<50 \mathrm{~mm}^{3}$ (5 mm in diameter) were ignored. Noncalcified nodules with a volume $>500 \mathrm{~mm}^{3}(>9.8 \mathrm{~mm})$ were considered positive and those in between $\left(50-500 \mathrm{~mm}^{3}\right)$ considered indeterminate. Participants with an indeterminate nodule had follow-up low-dose CT 6 weeks to 4 months later and at that time, the VDT was calculated. Pre-existing nodules with a VDT $<400$ days tested positive, and nodules with a VDT of 400-600 days were indeterminate and were rescheduled for a follow-up CT 1 year later (fig. 1). Sensitivity of the test after the first round was $94.6 \%$ and the negative predictive value

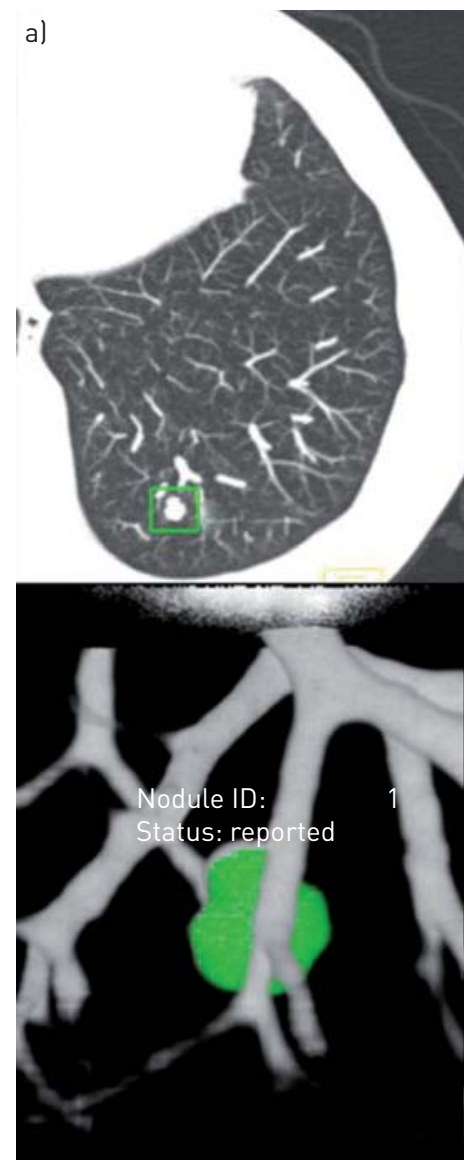

b)
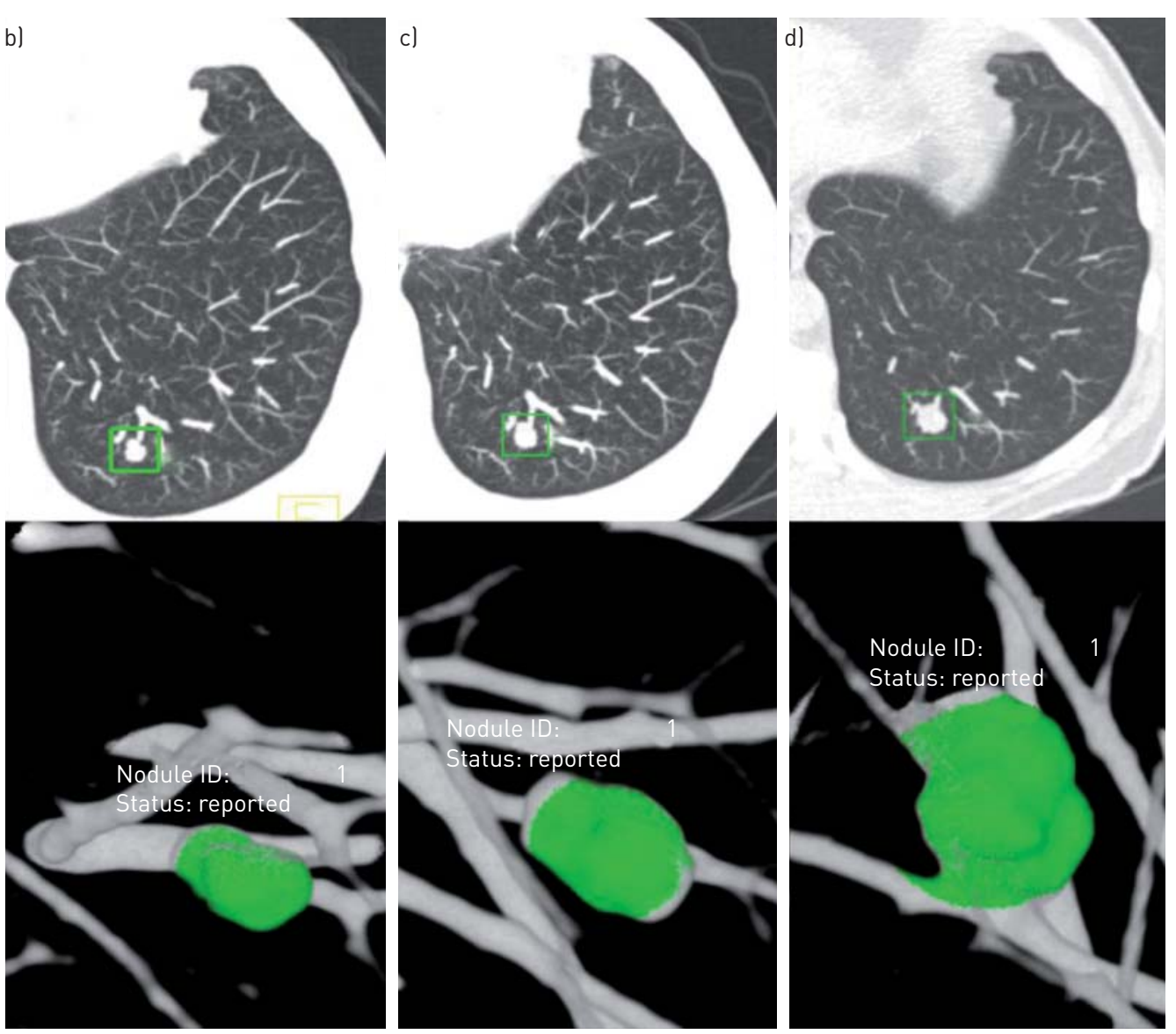

FIGURE 1 Three-dimensional assessment of computed tomography screening-detected lung cancer. a) An indeterminate nodule measuring 258 mm ${ }^{3}$ was detected at baseline in a 65-year-old current smoker in the NELSON trial [26]; b) at the 3-month follow-up examination, the nodule measured 270 mm $^{3}$ (volume doubling time (VDT) 1465 days, negative screen result); c) 1 year after baseline, the volume was $424 \mathrm{~mm}^{3}$ (VDT 528 days); and d) 2 years later it measured $1139 \mathrm{~mm}^{3}$ (VDT 289 days, positive test). Subsequent work-up revealed stage IA adenocarcinoma. 
was $99.9 \%$, while $2.6 \%$ of screened patients underwent higher-level investigation in the baseline round and $1.8 \%$ in the second round. At the second round, the positive predictive value for malignancy in solid nodules with a volume of $50-500 \mathrm{~mm}^{3}$ and VDT $<400$ days was $63 \%[27,28]$.

Since even benign lesions may demonstrate growth [18], several workup protocols also include positron emission tomography (PET)-scan and CT-guided percutaneous core biopsy as downstream tests to increase specificity [29-33].

The utility of PET scans in the differential diagnosis of benign and malignant lung nodules has been repeatedly confirmed and recently endorsed by the American College of Chest Physicians [21, 22, 34]. Despite some variability related to the chosen cut-off for the standardised uptake value (SUV) and to technical details, the reported sensitivity of PET imaging for lung cancer presenting as a solitary pulmonary nodule (SPN) is consistently high (80-100\%), while specificity is more variable (40-100\%). In a prospective study of 532 participants with newly detected SPNs, a sensitivity and specificity of 0.92 and 0.82 were reported for PET scan, versus 0.96 and 0.41 , respectively, for CT, and the area under the curve was 0.93 for PET scan and 0.82 for CT $(\mathrm{p}<0.0001)$. The negative predictive value of PET for lung cancer was 0.89 , while the positive predictive value was 0.86 [35].

Because the limit of detection with old-generation PET scanners is $\sim 10 \mathrm{~mm}$ (5-7 mm with newer PET-CT equipment), sensitivity is low for small tumours, which may particularly be missed when located in lower lung portions, where respiratory movements could prevent acquisition of an adequate image [36, 37]. In addition, neuroendocrine tumours and those with a predominant lepidic growth pattern on pathological examination, formerly known as bronchioloalveolar carcinomas [38], have low fluorodeoxyglucose (FDG) uptake, possibly due to the reduced number of cellular receptors involved in FDG internalisation, making PET scanning inadequate for carcinoid tumours and ground-glass lesions, unless the lesion has a sizeable solid component [39-43].

Rather than in the early detection of lung cancer, the value of PET scanning is thus mainly in reducing the rate of unnecessary invasive intervention for suspicious lesions after an adequate radiological workup [44].

It should also be remembered that some infectious or inflammatory lesions may show a significant FDG uptake, in the range observed in malignancy [45], and that in some cases an antibiotic trial may be worthwhile prior to proceeding to percutaneous or surgical biopsy (fig. 2).

Transbronchial or CT-guided percutaneous lung biopsy, video-assisted thoracoscopy (VATS) or thoracotomy with nodule removal and frozen sections are eventually considered if the lesion is still deemed suspicious based on all previous testing.

In most CT screening programmes, surgical biopsies carried out to confirm malignancy result in a benign nodule diagnosis in 15-25\% of cases, but the rate can be even higher [28, 30-33, 46, 47].

Not surprisingly, this occurrence is also relatively common in routine clinical practice due to the frequent discovery of incidental nodules in the CT era. For example, in a recent report $15 \%$ of lung resections in an

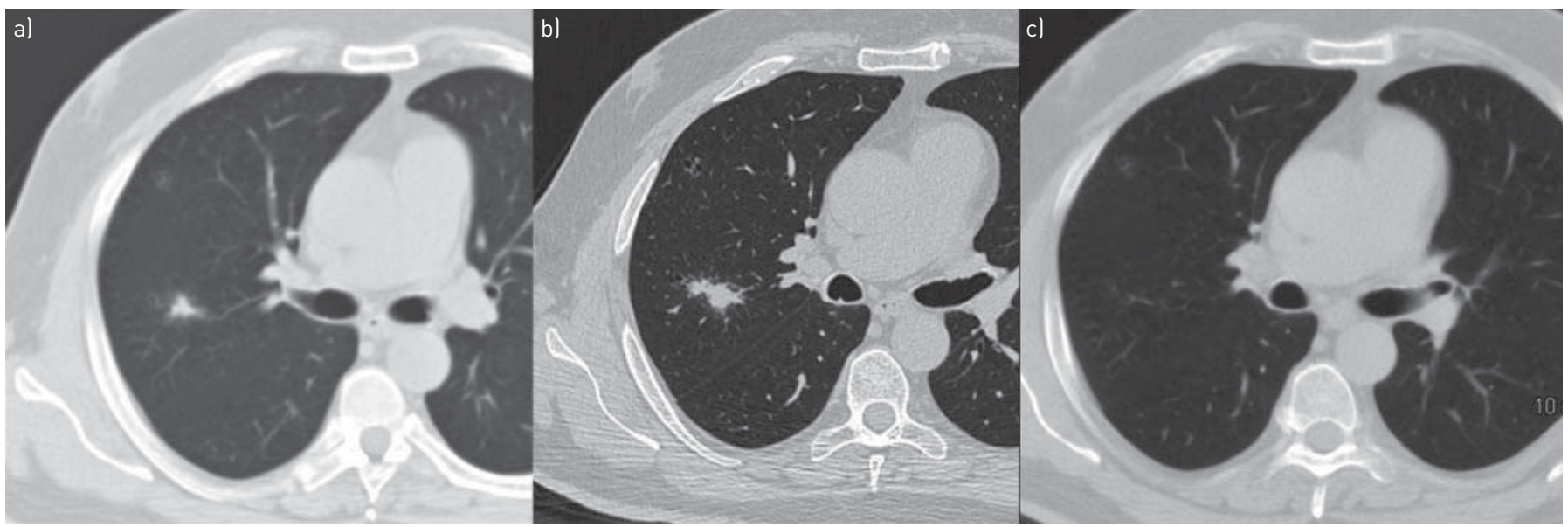

FIGURE 2 Role of positron emission tomography (PET) scanning in reducing unnecessary invasive procedures. a) Indeterminate lung nodule, measuring $13 \times 9 \mathrm{~mm}$, detected in a 70-year-old former smoker in the DANTE trial. Antibiotics were given and b) the computed tomography (CT) scan was repeated 45 days later, at which time the lesion measured $25 \times 12 \mathrm{~mm}$, had an irregular shape and spiculated margins. However, a PET scan showed no fluorodeoxyglucose uptake. 2 months later the lesion was fading and c) 10 months later it was no longer visible. 
academic hospital were carried out for clinically detected, harmless lesions [48]; a low threshold for lung biopsy in fact leads to high rates of "futile" invasive procedures in any setting.

Surgical biopsy in doubtful cases is prompted by fear that unrecognised lung cancer may progress beyond curability while being followed; however, the risk is low if the tumour characteristics favour slow growth, and the time frame for a thorough evaluation is reasonable. Only 6\% of CT-detected lung cancers would progress beyond stage I within 1 year according to recent reports [32, 49]; in addition, delaying treatment for up to 90 days does not seem to reduce survival chances in stage I-II lung cancer patients [50].

Multistep nodule management protocols developed in the screening setting have been successful in reducing unnecessary invasive procedures while retaining a high sensitivity for early lung cancer, and may be useful in the clinical setting as well.

Ideally, the diagnostic workup of incidental and screening-detected undetermined pulmonary nodules might be the same.

\section{Discriminating between slow-growing and aggressive lung cancer}

As yet, there are no validated biological indicators that could allow us to predict the clinical course of an individual lung cancer patient without therapy, unless the latter is intentionally left untreated for a sufficiently long period of time. Nonetheless, a number of features suggest that we could be dealing with a slow-growing tumour.

\section{Growth rate}

Tumour growth rate is intuitively the most important factor but reproducibility of nodule volume measurements is of critical importance, especially with small nodules.

$3 \mathrm{D}$ volume measurements are superior to $2 \mathrm{D}$ diameter measurements in terms of accuracy and reproducibility, because the whole nodule is analysed and not just its maximum diameter in an axial plane and because growth can be assessed more easily even if the nodule is nonspherical or if it grows asymmetrically [51-53]. Semiautomated or fully automated 3D volume evaluation is applicable with solid lesions [54] with a margin of error of $25-30 \%$ for repeat same-nodule assessments, which decreases with increasing nodule size. Although not negligible, this error margin is less than that in 2D assessments.

However, for focal ground-glass lesions, growth estimates are still largely based on 2D assessments because volume measurement variability with volumetric software is too high. Alternative methods based on changes in mass measurement (nodule volume $\times$ density) or CT attenuation values have been proposed [55-57].

\section{Morphological features}

CT-detected pulmonary nodules are nowadays classified as solid and subsolid, the latter also commonly termed ground-glass lesions or opacities (GGOs) [58].

The definition is based on whether the lesion completely obscures the underlying lung parenchyma (solid nodule) or normal parenchymal structures can still be seen through a hazy area of increased lung attenuation (subsolid nodule). This area may be inhomogeneous, i.e. present an inner solid component and a hazy ground-glass area around it, in which case it would also be called a part-solid nodule or mixed GGO; or it may be completely hazy, in which case the lesion would also be called nonsolid, or a pure GGO (fig. 3).

Solid lesions tend to progress faster than part-solid lesions and part-solid lesions tend to grow faster than nonsolid ones $[10,55]$, so in fact slow-growing lung cancers more commonly appear as focal ground-glass lesions in CT scans.

Histologically, ground-glass lesions correspond to the spectrum of tumours with lepidic-predominant growth, which includes their putative precursor atypical adenomatous hyperplasia, adenocarcinoma in situ (AIS), minimally invasive adenocarcinoma (MIA) and lepidic-predominant, invasive adenocarcinoma [38].

Current evidence suggests that the presence and size of any solid component in a ground-glass lesion are prognostically more relevant than whole tumour area, because they correlate better with local invasion at pathological examination, nodal metastasis, progression and post-resection survival [15, 43, 59-61]. Progression of ground-glass lesions may become manifest as an increase in size or density of the whole tumour area, of its solid component or as a combination of these.

In fact, the likelihood of local progression is low over several years, especially with pure ground-glass lesions. In three recent reports, progression of pure GGOs occurred in only $12-24 \%$ of the patients after 40-59 months, while $46-55 \%$ of mixed GGOs progressed over the same period [62-64]. 


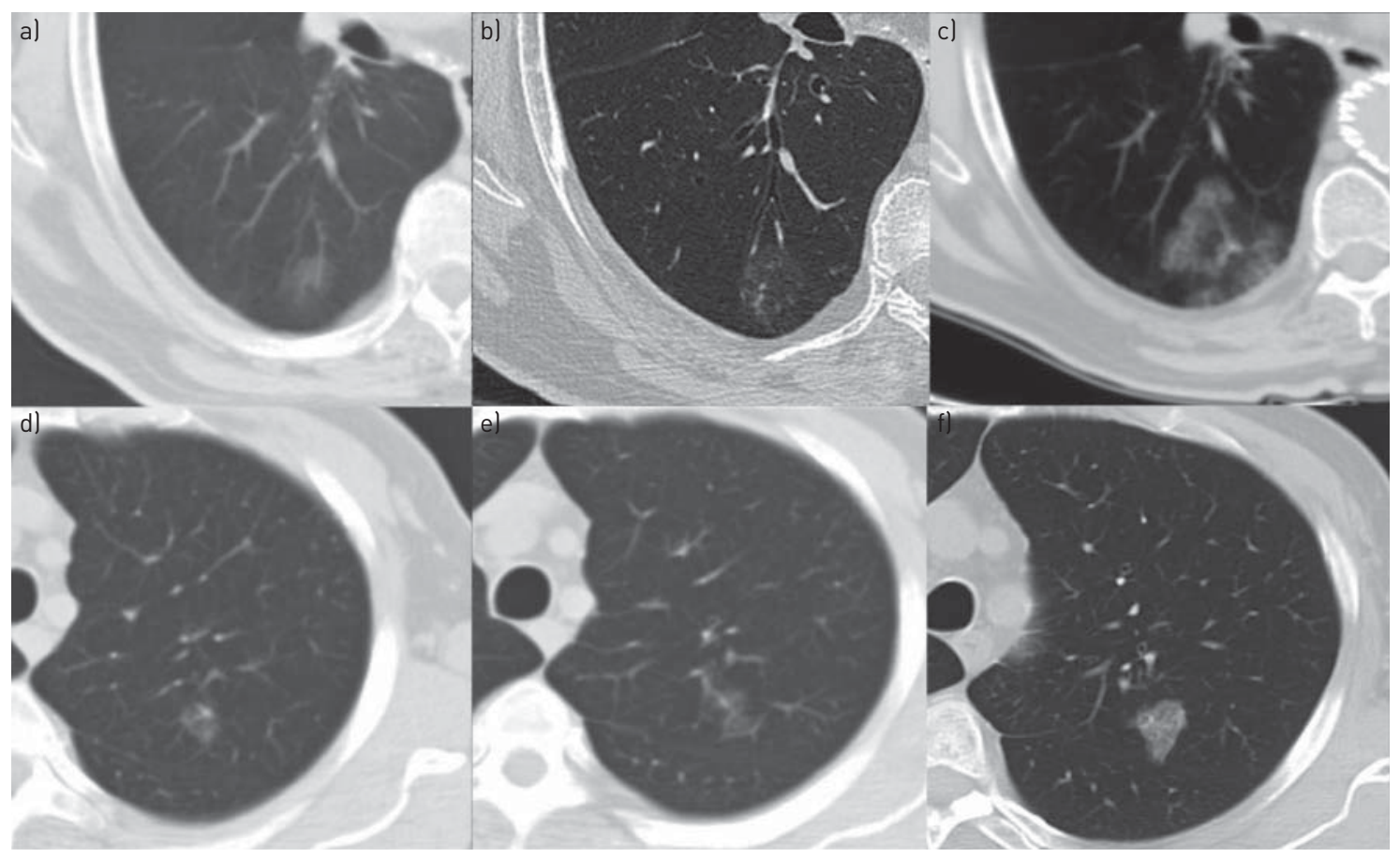

FIGURE 3 Slow evolution of nonsolid lung cancer (focal ground-glass lesions). a) Screening-detected pure ground-glass lesion in a 68-year-old former smoker. b) Follow-up was continued because of significant cardiovascular comorbidity until c) frank enlargement and increased density became evident, at age 77 years. Video-assisted thoracoscopic (VATS) wedge resection was carried out, and pathology revealed a 5.4-cm mucinous adenocarcinoma with lepidic and papillary aspects. The patient is currently disease-free 10 years after initial detection and 10 months after resection. d) Screening-detected focal ground-glass lesion in a 63-year-old former smoker, which e) did not change significantly over 3 years and was interpreted as focal fibrosis. f) 6 years after initial detection, the lesion had increased in size and density, and a positron emission tomography scan demonstrated fluorodeoxyglucose uptake. Percutaneous core biopsy was positive and VATS lobectomy was performed confirming stage IA adenocarcinoma with predominant lepidic features. The patient was disease-free 40 months after surgery.

In one such series [64], progression of pure GGOs was noted in 12 out of 89 patients over a median (range) follow-up period of 59 (25-140) months. Eight out of 11 lesions that were eventually resected in these 12 patients were either AIS $(n=2)$ or MIA $(n=6)$. Stage IA invasive adenocarcinoma was found in two patients; only one had progressed beyond stage I.

Thus, follow-up CT examinations at 6-month intervals are reasonably safe for GGOs, especially if the solid component is absent or minimal and the diameter is $<30 \mathrm{~mm}$ [65], but since progression may become evident after years (fig. 4), no time limit can be recommended for discontinuing surveillance [66].

Variability is high under any circumstances and solid nodules too may grow very slowly (fig. 4), but more careful monitoring is warranted in such cases. If follow-up is chosen, a 3-month interval before the first follow-up CT is reasonable [28] and subsequent management should be based on serial VDT determinations.

\section{FDG uptake}

The prognostic role of PET scanning in nonsmall cell lung cancer (NSCLC) has been assessed in a recent meta-analysis [67], which showed that the SUV of the primary tumour correlates with prognosis. Although these findings need further confirmation, they suggest that PET may be more useful than conventional imaging for prognostic purposes in locally advanced disease.

A correlation between pre-operative FDG uptake, pathological stage, probability of nodal metastasis and outcomes has also been reported for the spectrum of adenocarcinoma associated with focal GGOs and for stage I NSCLC in general [43, 61, 68-71].

TANN et al. [72] reported on a significant relationship between tumour growth rate as measured by serial CT scans and tumour metabolic activity as measured by FDG uptake for stage I lung cancer. In this series, only three $(6 \%)$ out of 51 cancers were classified as bronchoalveolar carcinoma.

VERONESI et al. [18] also recently reported that 44\% of PET-negative tumours had a VDT $>400$ days in their series, and a very favourable outcome was observed for tumours with a VDT $>200$ days and a negative PET scan. The proportion of lepidic-predominant tumours was not reported in this study. 


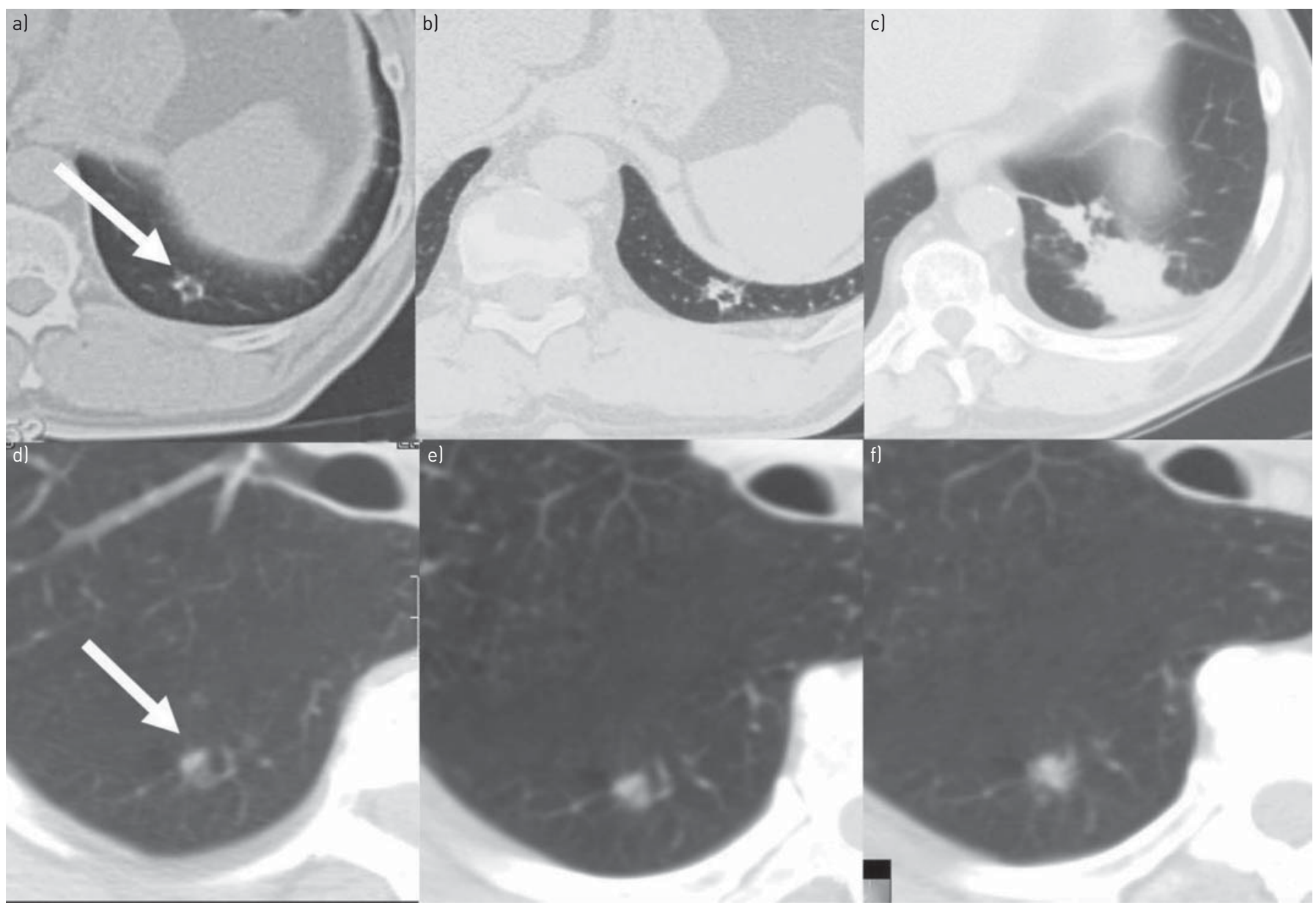

FIGURE 4 Slow evolution of small solid lung cancer. a-c) Screening-detected 1-cm excavated lesion (arrow) in a 71-year-old male smoker. b) 2 years after detection, modest increases in size and fluorodeoxyglucose uptake were demonstrated. Computed tomography (CT)-guided biopsy was recommended but the patient refused and discontinued follow-up. c) 6 years later a new CT scan was obtained, showing overt progression. Lobectomy was performed, and pathology showed stage III adenocarcinoma. The patient died with liver metastasis 1 year after surgery and 9 years after the initial detection of the tumour, at age 80 years. d) Sub-centimetre lesion in the right lower lobe (arrow) of a 64-year-old male patient in the DANTE trial who had undergone prior left lower lobectomy for stage IA adenocarcinoma at the age of 61 years. e) The lesion was retrospectively visible but smaller in a CT scan obtained at age 62 years. Follow-up was continued for several years because of the patient's own preferences. f) At age 67 years, the lesion had grown to $12 \mathrm{~mm}$. Anatomic segmentectomy was performed and an additional 4-mm nodule in the upper lobe was excised. Pathology was multifocal stage IA adenocarcinoma with predominant lepidic features. The patient was alive and well 12 months after the second lung resection.

Since carcinoid tumours and ground-glass lesions often do not take up FDG significantly and both exhibit a particularly favourable clinical course, it is tempting to infer that FDG-PET may be used as an additional tool to decide on the aggressiveness of management, at least for early-stage disease.

\section{Histology}

Several authors have reported a significant correlation between histological type and tumour growth rate. For example, squamous cancer is generally faster-growing than adenocarcinoma, but there is a significant overlap across all tumour types $[4,10,11,13,14,16,17,49,73,74]$. Consequently, prediction of tumour behaviour cannot be reliably based on histological differentiation.

The only exception may be with tumours showing lepidic growth, but even in such cases, stromal invasion may be impossible to estimate accurately on a small biopsy or on frozen sections [38]; thus, a sensible management plan should be devised on clinical grounds and based on typical imaging results.

\section{The clinical context}

Tumours that are detected due to symptoms or by a chest radiograph tend to be solid, $>1 \mathrm{~cm}$ or $>500 \mathrm{~mm}^{3}$, and to have short VDTs $[4,9,75]$. 
In contrast, a significant proportion of CT-screening detected tumours, prevalent cancers especially, have long VDTs. In the Pittsburgh Lung Screening Study [17], 28 (67\%) out of 42 baseline-screen cancers had VDTs $>365$ days. Nonprevalent cases, i.e. those detected after a negative baseline screen, tend to be faster (table 1).

Little is known to date about the growth rates of small lung cancers incidentally detected by a CT scan obtained for unrelated reasons, but since small, slow-growing tumours are more likely to be detected incidentally by CT, intuitively they might be assimilated to screening-detected prevalent cancers.

Ground-glass lesions and small, slow-growing nodules that are often missed by chest radiographic examination are instead more easily detected by CT because of a longer "window of detection", the time interval from when they become potentially detectable by the screening test to when symptoms appear, i.e. due to length-time bias [76]. The associations between detection by CT scan, long VDTs and better outcomes are therefore due to selection.

\section{Areas of uncertainty}

The exponential model of tumour growth, which implies a constant cell replication rate throughout the life of the tumour, does not fully explain our clinical observations, and tumour growth rate, although important, may not be all we need to know.

A primary tumour with a long VDT should remain surgically curable for a longer period of time, provided that growth is constant, and that nodal spread or distant metastasis do not occur in the meantime.

Lung cancer growth may in fact be nonlinear in some cases, and some tumours may actually show an accelerated growth phase after a period of constant slow increase in size, as demonstrated by LiNDELL et al. [12]. Such phenomena have also been occasionally observed in the DANTE and the NELSON trials.

It may be speculated that a slow growth rate is also associated with a lower rate of dissemination because the frequency of nodal metastasis is directly related to the size of the primary tumour, and current evidence suggests that this is true for the spectrum of lepidic tumours; however, such a relationship has not been investigated in depth for other histotypes.

Tumours with shorter VDTs indeed have higher 5-year recurrence rates after resection [11, 14, 73], but slow-growing lung cancers may merely recur later than fast-growing ones.

The information provided by PET in assessing tumour biology and aggressiveness, although promising, is, to date, still limited. Tumour growth rates have been correlated with FDG uptake in two studies only [18, 72] and correlations between FDG uptake and outcomes have only been explored after treatment. To our knowledge, no published study exists correlating FDG uptake with the natural history of untreated lung cancer.

\section{Estimating risks and benefits}

It is likely that we will end up treating most patients harbouring a (putative) slow-growing lung cancer, but because age and comorbidities may outweigh cancer progression in such patients [77-79], individual risk factors, estimated treatment-related morbidity and mortality and expected long-term outcomes for each available therapeutic option should be considered even more carefully than usual (figs 3-5).

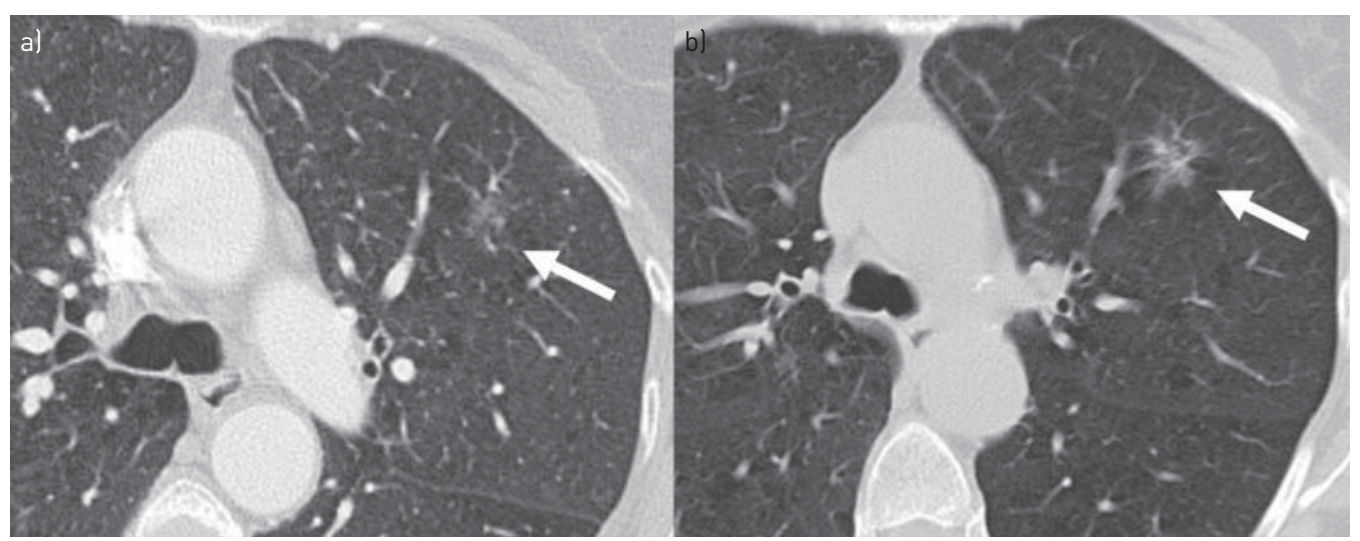

FIGURE 5 A typical controversial case. A 65-year-old female patient with moderately compromised lung function. In 2008 , at the age of 61 years, limited resection of the right upper lobe was carried out for bronchioalveolar carcinoma with minimal invasive component. a) At that time a small infiltrate (arrow) was visible in the left upper lobe; b) 4 years later an increase in size and density is evident. The patient prefers to remain in follow-up; should we press her to obtain a tissue diagnosis and, if malignant (highly likely), treat her? If yes, how? 
A thorough evaluation of the patient's underlying condition should be followed by pulmonary and cardiac function testing according to the guidelines published by the major international thoracic societies [80-82].

In general terms, the 5-year local recurrence rate is $13-30 \%$ and overall 5 -year survival is roughly $50-70 \%$ after lobectomy for early-stage lung cancer [83-85]. Post-operative complications occur after lobectomy in $40-55 \%$ of the cases; the reported 30 -day mortality is $1.3-4.2 \%$ and rises to $5.4-7.8 \%$ after pneumonectomy [86-90]. 90-day mortality adds another $2-3 \%$ to the toll, mainly due to cardiovascular events occurring after discharge, but these data are seldom reported $[89,91]$. Several risk models have been developed to stratify patients based on their surgical risk; however, their performance is less than ideal [92-94].

Moreover, quality of life and functional wellbeing indicators may still show a detrimental impact of major lung resection up to 2 years post-operatively in a significant proportion of patients [95-99]. In one study, $24 \%$ and $11 \%$ of long-term cancer survivors still experienced moderate and severe limitations, respectively, in their daily activities due to residual dyspnoea [100].

The risks both of perioperative complications and long-term disability increase several-fold in patients with advanced age, active smoking, poor lung function, prior myocardial infarction, extensive resection volume, previous lung resection and a high comorbidity burden.

Comorbidity is also an independent predictor of stage-specific lung cancer survival. In a Danish cohort of 3152 patients [101], 5-year survival for pT1 disease was $69 \%$ if the Charlson comorbidity score was $0 ; 54 \%$ if the score was $1-2$; and $38 \%$ if it was $\geqslant 3$. Similar figures were reported for N0, N1 and N2 disease. The Charlson score can be calculated manually or through a free online application [102].

\section{Tailored therapeutic approaches}

Surgical options

Lobectomy is currently the standard of care because sublobar resections (wedge resection and segmentectomy) resulted in a significantly higher local recurrence rate compared with lobectomy in the only randomised trial conducted so far, in 1995 [103].

Easier patient acceptance of minimally invasive approaches led to the extension of the indications of VATS surgery to early-stage lung cancer resection with curative intent [104, 105].

Technically, VATS lobectomy is not a compromise procedure as the resection volume is no less than with open lobectomy, and lymphadenectomy should ideally be the same, but surgical trauma and post-operative pain are definitely reduced, and complication rates are indeed lower in most recent reports that compare the two techniques. Mortality rates of $\sim 1 \%$ are regularly reported, with few exceptions. The benefits of VATS are more evident in patients with advanced age, poor lung function and a higher comorbidity burden [105-112]. In addition, lung cancer recurrence rates with VATS do not seem to be increased, and may even be decreased compared with lobectomy via the standard thoracotomy approach [112-114].

Recent reports suggest that local control and 5-year survival with sublobar resections, which limit the loss of functional lung tissue, may be equivalent to those obtained with lobectomy in selected cases, especially in elderly patients or in those with a compromised respiratory function [115-119].

Wedge resection is a simple procedure in which a portion of lung parenchyma encompassing the nodule is excised, normally with the aid of surgical staplers. For pure GGOs, 100\% 5-year recurrence-free survival has been reported [120,121], although late recurrences may be observed [122]. Wedge resection may also be equivalent to lobectomy for patients with subcentimetre solid nodules [123, 124].

Segmentectomy is the removal of a complete pulmonary segment, and requires individual division of segmental vessels and bronchi at their origin. It allows resection of more centrally located nodules with wider safety margins and the dissection of hilar lymphatics.

Advanced age, a nodule measuring $<2 \mathrm{~cm}$, a mixed ground-glass lesion with $<75 \%$ solid component and a tumour-free margin of $\geqslant 2 \mathrm{~cm}$ are favourable indications for segmentectomy. Post-operative mortality for segmentectomy is $0-1 \%$, with few exceptions [118, 125-129].

Limited resections have recently been endorsed for tumours with lepidic growth, based on the new International Association for the Study of Lung Cancer/American Thoracic Society/European Respiratory Society classification of adenocarcinoma [130]. Either alone or in combination with lobectomy, they may also be appropriate for patients with multifocal slow-growing tumours, based on the assumption that they represent independent foci of lung cancer rather than metastasis [131]. 
However, evidence in favour of limited resections is still inconclusive. Two large multi-institutional randomised trials are currently comparing limited resections versus lobectomy for early-stage lung cancer in the USA and in Japan $[132,133]$.

\section{Nonsurgical options}

Conventional radiotherapy had limited efficacy on local control and survival of lung cancer patients, and was traditionally reserved for medically inoperable patients.

However, modern stereotactic radiotherapy techniques allow for a much more precise administration of high radiation doses to the tumour, while substantially limiting the exposure of adjacent tissues. Reported 3 -year local control rates for small peripheral lesions are in the range of $80-90 \%$ [134, 135].

Advantages of stereotactic radiotherapy include short duration of treatment, minimal patient discomfort, limited pulmonary toxicity, low morbidity in the short term and low impact on quality of life.

Potential disadvantages are the limited availability of long-term follow-up data [136], lack of information about micrometastatic disease in lymphatics, and an increased risk $(\sim 10 \%)$ of severe and fatal adverse events when centrally located lesions are treated $[137,138]$. Local control and complication rates are dose-dependent.

Two randomised trials are currently exploring whether stereotactic radiotherapy may be equivalent to sublobar resection [139] or lobectomy [140] in patients who can tolerate surgery.

Radiofrequency ablation (RFA), microwave ablation and cryotherapy are means of thermal tissue destruction. RFA has been employed for $>10$ years [141] and is the best studied of all such treatments. High intralesional temperatures $\left(90^{\circ} \mathrm{C}\right.$ for $\left.16-27 \mathrm{~min}\right)$ are obtained by means of a needle electrode implanted percutaneously into the tumour under CT guidance, under general anaesthesia or conscious sedation.

Advantages of RFA include limited trauma, no radiation exposure, the possibility of retreating recurrences and minimal impact on respiratory function, although reports are sometimes contradictory in this respect [142-144]. Complications such as pneumothorax and pleural effusion are frequent $(\sim 30 \%)$, but mostly mild. However, severe complications may occur in 5-9\% of patients. Mortality after RFA is $0.5-2.6 \%$, mainly due to acute respiratory failure or massive haemorrhage [144-146].

Local recurrences occur within 3 years in $30-50 \%$ of cases, but results are better with nodules measuring $<3 \mathrm{~cm}$ [144]. Local control rates with RFA seem to be lower than with stereotactic radiotherapy [147].

\section{Psychological profiles}

Age, personality traits, social wellbeing, parenthood and risk perception have been linked to the acceptance of treatment by patients $[148,149]$. Some patients with slow-growing lung cancer will accept or even solicit an aggressive approach, while others will be comfortable with being followed until the situation evolves.

As always, patients should be encouraged to express their expectations and fears and be educated regarding their condition in order to share the decision. However, patient preferences for exhaustive information and for an active role in the decision-making process vary widely, and many patients in fact prefer delegating the responsibility for the final decision [150].

With all the necessary clinical experience at hand, and even when mathematical models are used to help estimate the risk-benefit ratios of available options [20], the cut-off value will vary according to personal beliefs and inclinations of patients and doctors (fig. 5).

\section{Conclusions}

With all patients, the foundation of clinical decision-making rests on a careful balance of competitive risks related to the natural course of the disease, life expectancy and impact of treatment.

The management of lung cancer patients has been traditionally modelled by the tenet that their condition is almost always rapidly lethal. Once the diagnosis is established (and occasionally, even before that) immediate action is needed, and treatment-related risks may be acceptable, even if high, in the face of almost certain death in the short term.

Until recently, slow-growing lung cancer has been rarely recognised in routine clinical practice for several possible reasons: a lesion that does not grow visibly for $\geqslant 2$ years would probably be interpreted as nonmalignant [22]; patients in a poor underlying condition may be left with an undiagnosed slow-growing cancer; and as soon as a biopsy shows malignant cells, all patients in a reasonable underlying condition will be referred for definitive treatment, and no conclusion can be reached about their natural course in the absence of therapy. Evidence on the natural history of untreated lung cancer may thus be biased by involuntary case selection [151]. 
TABLE 2 Elements that favour observation, tailored options or standard management for patients with putative slow-growing lung cancer

\section{Observation}

\section{Age \\ Comorbidity burden}

Detection

Size

Morphology

VDT

PET/SUV

Surgical options

Nonsurgical options

Psychological profile
Relatively old High

Relatively old
High
Screening or incidental CT finding
Relatively small
Nonsolid
No progression or long VDT\#
PET-negative or low SUV
Unsuitable for sublobar resection
Comfortable with being followed

Tailored options

Relatively old ${ }^{\#}$ High

Screening or incidental CT finding

Relatively small

Part-solid

No progression or long VDT\#

PET-negative or low SUV

Suitable for sublobar resection

SBRT or RFA available

Anxious, prefers certainty
Standard management
Relatively young $\#$ Low

Clinically detected

Relatively large Solid

Relatively short VDT

PET-positive, high SUV\#

Suitable for VATS lobectomy

Anxious, prefers certainty

VDT: volume doubling time; PET: positron emission tomography; SUV: standardised uptake value; CT: computed tomography; SBRT: stereotactic body radiation therapy; RFA: radiofrequency ablation; VATS: video-assisted thoracoscopy. " : no conventional limit.

It appears that the biological behaviour of lung cancer instead spans across a spectrum, from fast and highly lethal to slow-growing and indolent, and that the mode of detection determines which we are more likely to be dealing with [75]. Current trends in health care suggest that patients possibly harbouring the latter will be increasingly frequently encountered [152, 153].

Ideally, our approach should thus be adjusted according to a new estimate of the probability that the cancer under consideration will cause harm within a given time frame (normally, within the patient's expected lifespan), together with an estimate of the projected results of each strategy and of its potential impact on the patient's life expectancy and wellbeing (table 2).

Because lung cancer can be rapidly fatal and because individual predictors of tumour progression are not yet available, most patients will still be treated according to standard guidelines. Further research and specific prospective studies are needed on the value of volume-based tumour growth assessment by CT and of PET scanning for the identification of patients with relatively unaggressive lung cancer, and tailored management strategies (standard treatment, limited resection, conservative options or observation) based on VDT and FDG uptake still have to be validated.

Yet the elements discussed above may be taken into account to devise a personalised, reasonable management approach and the timing of intervention, if any, for these peculiar cases. Clinical experience, intuition and empathy, though immeasurable, will be always needed in order to make the best possible choice for the patient.

\section{References}

1 McGarry RC, Song G, des Rosiers P, et al. Observation-only management of early stage, medically inoperable lung cancer: poor outcome. Chest 2002; 121: 1155-1158.

2 Motohiro A, Ueda $\mathrm{H}$, Komatsu $\mathrm{H}$, et al. Prognosis of non-surgically treated, clinical stage I lung cancer patients in Japan. Lung Cancer 2002; 36: 65-69.

3 Raz DJ, Zell JA, Ou SH, et al. Natural history of stage I non-small cell lung cancer: implications for early detection. Chest 2007; 132: 193-199.

4 Hayabuchi N, Russell WJ, Murakami J. Slow-growing lung cancer in a fixed population sample. Radiologic assessments. Cancer 1983; 52: 1098-1104.

5 Kubík AK, Parkin DM, Zatloukal P. Czech Study on Lung Cancer Screening: post-trial follow-up of lung cancer deaths up to year 15 since enrollment. Cancer 2000; 89: Suppl. 11, 2363-2368.

6 Fontana RS, Sanderson DR, Woolner LB, et al. Screening for lung cancer. A critique of the Mayo Lung Project. Cancer 1991; 67: Suppl. 4, 1155-1164.

Welch HG, Black WC. Overdiagnosis in cancer. J Natl Cancer Inst 2010; 102: 605-613.

8 Geddes DM. The natural history of lung cancer: a review based on rates of tumour growth. Br J Dis Chest 1979; 73: $1-17$.

9 Yankelevitz DF, Kostis WJ, Henschke CI, et al. Overdiagnosis in chest radiographic screening for lung carcinoma: frequency. Cancer 2003; 97: 1271-1275.

10 Hasegawa M, Sone S, Takashima S, et al. Growth rate of small lung cancers detected on mass CT screening. $\mathrm{Br} J$ Radiol 2000; 73: 1252-1259.

11 Jennings SG, Winer-Muram HT, Tann M, et al. Distribution of stage I lung cancer growth rates determined with serial volumetric CT measurements. Radiology 2006; 241: 554-563.

12 Lindell RM, Hartman TE, Swensen SJ, et al. Five-year lung cancer screening experience: CT appearance, growth rate, location, and histologic features of 61 lung cancers. Radiology 2007; 242: 555-562. 
13 Honda O, Johkoh T, Sekiguchi J, et al. Doubling time of lung cancer determined using three-dimensional volumetric software: comparison of squamous cell carcinoma and adenocarcinoma. Lung Cancer 2009; 66: 211-217.

14 Mikita K, Saito H, Sakuma Y, et al. Growth rate of lung cancer recognized as small solid nodule on initial CT findings. Eur J Radiol 2012; 81: e548-e553.

15 Sone S, Hanaoka T, Ogata H, et al. Small peripheral lung carcinomas with five-year post-surgical follow-up: assessment by semi-automated volumetric measurement of tumour size, CT value and growth rate on TSCT. Eur Radiol 2012; 22: 104-119.

16 Henschke CI, Yankelevitz DF, Yip R, et al. Lung cancers diagnosed at annual CT screening: volume doubling times. Radiology 2012; 263: 578-583.

17 Wilson DO, Ryan A, Fuhrman C, et al. Doubling times and CT screen-detected lung cancers in the Pittsburgh Lung Screening Study. Am J Respir Crit Care Med 2012; 185: 85-89.

18 Veronesi G, Maisonneuve P, Bellomi M, et al. Estimating overdiagnosis in low-dose computed tomography screening for lung cancer: a cohort study. Ann Intern Med 2012; 157: 776-784.

19 Henschke CI, Yankelevitz DF, Libby DM, et al. Survival of patients with stage I lung cancer detected on CT screening. N Engl J Med 2006; 355: 1763-1771.

20 Ost DE, Gould MK. Decision making in patients with pulmonary nodules. Am J Respir Crit Care Med 2012; 185: 363-372.

21 Wahidi MM, Govert JA, Goudar RK, et al. Evidence for the treatment of patients with pulmonary nodules: when is it lung cancer? Chest 2007; 132: Suppl. 3, 94S-107S.

22 Gould MK, Fletcher J, Iannettoni MD, et al. Evaluation of patients with pulmonary nodules: when is it lung cancer? Chest 2007; 132: Suppl. 3, 108S-130S.

23 Wisnivesky JP, Yankelevitz D, Henschke CI. Stage of lung cancer in relation to its size: part 2. Evidence. Chest 2005; 127: 1136-1139.

24 Yankelevitz DF, Reeves AP, Kostis WJ, et al. Small pulmonary nodules: volumetrically determined growth rates based on CT evaluation. Radiology 2000; 217: 251-256.

25 Revel MP, Merlin A, Peyrard S, et al. Software volumetric evaluation of doubling times for differentiating benign versus malignant pulmonary nodules. AJR AmJ Roentgenol 2006; 187: 135-142.

$26 \mathrm{Xu} \mathrm{DM}$, Gietema H, de Koning H, et al. Nodule management protocol of the NELSON randomised lung cancer screening trial. Lung Cancer 2006; 54: 177-184.

27 Xu DM, van der Zaag-Loonen HJ, Oudkerk M, et al. Smooth or attached solid indeterminate nodules detected at baseline CT screening in the NELSON study: cancer risk during 1 year of follow-up. Radiology 2009; 250: 264-272.

28 van Klaveren RJ, Oudkerk M, Prokop M, et al. Management of lung nodules detected by volume CT scanning. N Engl J Med 2009; 361: 2221-2229.

29 C.I. Henschke. International Early Lung Cancer Action Programme. Protocol Documents. http://ielcap.org/sites/ default/files/ielcap.pdf Date last updated: July 1, 2011.

30 Ashraf H, Dirksen A, Loft A, et al. Combined use of positron emission tomography and volume doubling time in lung cancer screening with low-dose CT scanning. Thorax 2011; 66: 315-319.

31 Infante M, Chiesa G, Solomon D, et al. Surgical procedures in the DANTE trial, a randomized study of lung cancer early detection with spiral computed tomography: comparative analysis in the screening and control arm. J Thorac Oncol 2011; 6: 327-335.

32 Veronesi G, Bellomi M, Veronesi U, et al. Role of positron emission tomography scanning in the management of lung nodules detected at baseline computed tomography screening. Ann Thorac Surg 2007; 84: 959-965.

33 Menezes RJ, Roberts HC, Paul NS, et al. Lung cancer screening using low-dose computed tomography in at-risk individuals: the Toronto experience. Lung Cancer 2010; 67: 177-183.

34 Gould MK, Maclean CC, Kuschner WG, et al. Accuracy of positron emission tomography for diagnosis of pulmonary nodules and mass lesions: a meta-analysis. JAMA 2001; 285: 914-924.

35 Fletcher JW, Kymes SM, Gould M, et al. A comparison of the diagnostic accuracy of 18F-FDG PET and CT in the characterization of solitary pulmonary nodules. J Nucl Med 2008; 49: 179-185.

36 Kim SC, Machac J, Krynyckyi BR, et al. Fluoro-deoxy-glucose positron emission tomography for evaluation of indeterminate lung nodules: assigning a probability of malignancy may be preferable to binary readings. Ann Nucl Med 2008; 22: 165-170.

37 Herder GJ, Golding RP, Hoekstra OS, et al. The performance of (18)F-fluorodeoxyglucose positron emission tomography in small solitary pulmonary nodules. Eur J Nucl Med Mol Imaging 2004; 31: 1231-1236.

38 Travis WD, Brambilla E, Noguchi M, et al. International Association for the Study of Lung Cancer/American Thoracic Society/European Respiratory Society: international multidisciplinary classification of lung adenocarcinoma. J Thorac Oncol 2011; 6: 244-285.

39 Khandani AH, Whitney KD, Keller SM, et al. Sensitivity of FDG PET, GLUT1 expression and proliferative index in bronchioloalveolar lung cancer. Nucl Med Commun 2007; 28: 173-177.

40 Song YS, Lee WW, Chung JH, et al. Correlation between FDG uptake and glucose transporter type 1 expression in neuroendocrine tumors of the lung. Lung Cancer 2008; 61: 54-60.

41 Chun EJ, Lee HJ, Kang WJ, et al. Differentiation between malignancy and inflammation in pulmonary ground-glass nodules: the feasibility of integrated ${ }^{18}$ F-FDG PET/CT. Lung Cancer 2009; 65: 180-186.

42 Kim TJ, Park CM, Goo JM, et al. Is there a role for FDG PET in the management of lung cancer manifesting predominantly as ground-glass opacity? AJR Am J Roentgenol 2012; 198: 83-88.

43 Okada M, Nakayama H, Okumura S, et al. Multicenter analysis of high-resolution computed tomography and positron emission tomography/computed tomography findings to choose therapeutic strategies for clinical stage IA lung adenocarcinoma. J Thorac Cardiovasc Surg 2011; 141: 1384-1391.

44 van't Westeinde SC, de Koning HJ, Thunnissen FB, et al. The role of the ${ }^{18} \mathrm{~F}$-fluorodeoxyglucose-positron emission tomography scan in the Nederlands Leuvens Longkanker screenings Onderzoek lung cancer screening trial. J Thorac Oncol 2011; 6: 1704-1712.

45 Bryant AS, Cerfolio RJ. The maximum standardized uptake values on integrated FDG-PET/CT is useful in differentiating benign from malignant pulmonary nodules. Ann Thorac Surg 2006; 82: 1016-1020. 
46 National Lung Screening Trial Research Team. Reduced lung-cancer mortality with low-dose computed tomographic screening. $N$ Engl J Med 2011; 365: 395-409.

47 Wilson DO, Weissfeld JL, Fuhrman CR, et al. The Pittsburgh Lung Screening Study (PLuSS): outcomes within 3 years of a first computed tomography scan. Am J Respir Crit Care Med 2008; 178: 956-961.

48 Kuo E, Bharat A, Bontumasi N, et al. Impact of video-assisted thoracoscopic surgery on benign resections for solitary pulmonary nodules. Ann Thorac Surg 2012; 93: 266-272.

49 Winer-Muram HT, Jennings SG, Tarver RD, et al. Volumetric growth rate of stage I lung cancer prior to treatment: serial CT scanning. Radiology 2002; 223: 798-805.

50 Quarterman RL, McMillan A, Ratcliffe MB, et al. Effect of preoperative delay on prognosis for patients with early stage non-small cell lung cancer. J Thorac Cardiovasc Surg 2003; 125: 108-113.

51 Marten K, Engelke C. Computer-aided detection and automated CT volumetry of pulmonary nodules. Eur Radiol 2007; 17: 888-901.

52 Revel MP, Bissery A, Bienvenu M, et al. Are two-dimensional CT measurements of small noncalcified pulmonary nodules reliable? Radiology 2004; 231: 453-458.

53 Reeves AP, Biancardi AM, Apanasovich TV, et al. The Lung Image Database Consortium (LIDC): a comparison of different size metrics for pulmonary nodule measurements. Acad Radiol 2007; 14: 1475-1485.

54 Marchianò $\mathrm{A}$, Calabrò $\mathrm{E}$, Civelli $\mathrm{E}$, et al. Pulmonary nodules: volume repeatability at multidetector CT lung cancer screening. Radiology 2009; 251: 919-925.

55 Oda S, Awai K, Murao K, et al. Computer-aided volumetry of pulmonary nodules exhibiting ground-glass opacity at MDCT. AJR Am J Roentgenol 2010; 194: 398-406.

56 de Hoop B, Gietema H, van de Vorst S, et al. Pulmonary ground-glass nodules: increase in mass as an early indicator of growth. Radiology 2010; 255: 199-206.

57 Zhang L, Yankelevitz DF, Carter D, et al. Internal growth of nonsolid lung nodules: radiologic-pathologic correlation. Radiology 2012; 263: 279-286.

58 Naidich DP, Bankier AA, MacMahon H, et al. Recommendations for the management of subsolid pulmonary nodules detected at CT: a statement from the Fleischner Society. Radiology 2013; 266: 304-317.

59 Suzuki K, Kusumoto M, Watanabe S, et al. Radiologic classification of small adenocarcinoma of the lung: radiologic-pathologic correlation and its prognostic impact. Ann Thorac Surg 2006; 81: 413-419.

60 Matsuguma H, Yokoi K, Anraku M, et al. Proportion of ground-glass opacity on high-resolution computed tomography in clinical T1 N0 M0 adenocarcinoma of the lung: a predictor of lymph node metastasis. $J$ Thorac Cardiovasc Surg 2002; 124: 278-284.

61 Tsutani Y, Miyata Y, Nakayama H, et al. Prognostic significance of using solid versus whole tumor size on highresolution computed tomography for predicting pathologic malignant grade of tumors in clinical stage IA lung adenocarcinoma: a multicenter study. J Thorac Cardiovasc Surg 2012; 143: 607-612.

62 Silva M, Sverzellati N, Manna C, et al. Long-term surveillance of ground-glass nodules: evidence from the MILD trial. J Thorac Oncol 2012; 7: 1541-1546.

63 Matsuguma $\mathrm{H}$, Mori $\mathrm{K}$, Nakahara R, et al. Characteristics of subsolid pulmonary nodules showing growth during follow-up with CT scanning. Chest 2013; 143: 436-443.

64 Chang B, Hwang JH, Choi YH, et al. Natural history of pure ground-glass opacity lung nodules detected by lowdose CT scan. Chest 2013; 143: 172-178.

65 Sawada S, Komori E, Nogami N, et al. Evaluation of lesions corresponding to ground-glass opacities that were resected after computed tomography follow-up examination. Lung Cancer 2009; 65: 176-179.

66 Min JH, Lee HY, Lee KS, et al. Stepwise evolution from a focal pure pulmonary ground-glass opacity nodule into an invasive lung adenocarcinoma: an observation for more than 10 years. Lung Cancer 2010; 69: 123-126.

67 Paesmans $\mathrm{M}$, Berghmans $\mathrm{T}$, Dusart $\mathrm{M}$, et al. Primary tumor standardized uptake value measured on fluorodeoxyglucose positron emission tomography is of prognostic value for survival in non-small cell lung cancer: update of a systematic review and meta-analysis by the European Lung Cancer Working Party for the International Association for the Study of Lung Cancer Staging Project. J Thorac Oncol 2010; 5: 612-619.

68 Okereke IC, Gangadharan SP, Kent MS, et al. Standard uptake value predicts survival in non-small cell lung cancer. Ann Thorac Surg 2009; 88: 911-915.

69 Dooms C, van Baardwijk A, Verbeken E, et al. Association between 18F-fluoro-2-deoxy-D-glucose uptake values and tumor vitality: prognostic value of positron emission tomography in early-stage non-small cell lung cancer. J Thorac Oncol 2009; 4: 822-828.

70 Kadota K, Colovos C, Suzuki K, et al. FDG-PET SUVmax combined with IASLC/ATS/ERS histologic classification improves the prognostic stratification of patients with stage I lung adenocarcinoma. Ann Surg Oncol 2012; 19: 3598-3605.

71 Nair VS, Barnett PG, Ananth L, et al. PET scan ${ }^{18} \mathrm{~F}$-fluorodeoxyglucose uptake and prognosis in patients with resected clinical stage IA non-small cell lung cancer. Chest 2010; 137: 1150-1156.

72 Tann M, Sandrasegaran K, Winer-Muram HT, et al. Can FDG-PET be used to predict growth of stage I lung cancer? Clin Radiol 2008; 63: 856-863.

73 Arai T, Kuroishi T, Saito Y, et al. Tumor doubling time and prognosis in lung cancer patients: evaluation from chest films and clinical follow-up study. Jpn J Clin Oncol 1994; 24: 199-204.

74 Sone S, Li F, Yang ZG, et al. Results of three-year mass screening programme for lung cancer using mobile low-dose spiral computed tomography scanner. Br J Cancer 2001; 84: 25-32.

75 Detterbeck FC, Gibson CJ. Turning gray: the natural history of lung cancer over time. J Thorac Oncol 2008; 3: 781-792.

76 Patz EF Jr, Goodman PC, Bepler G. Screening for lung cancer. N Engl J Med 2000; 343: 1627-1633.

77 Doll R, Peto R, Boreham J, et al. Mortality in relation to smoking: 50 years' observations on male British doctors. BMJ 2004; 328: 1519.

78 Sin DD, Man SF. Chronic obstructive pulmonary disease as a risk factor for cardiovascular morbidity and mortality. Proc Am Thorac Soc 2005; 2: 8-11.

79 Streppel MT, Boshuizen HC, Ocké MC, et al. Mortality and life expectancy in relation to long-term cigarette, cigar and pipe smoking: the Zutphen Study. Tob Control 2007; 16: 107-113. 
Brunelli A, Charloux A, Bolliger CT, et al. ERS/ESTS clinical guidelines on fitness for radical therapy in lung cancer patients (surgery and chemo-radiotherapy). Eur Respir J 2009; 34: 17-41.

81 Lim E, Baldwin D, Beckles M, et al. Guidelines on the radical management of patients with lung cancer. Thorax 2010; 65: Suppl. 3, iii1-iii27.

82 Colice GL, Shafazand S, Griffin JP, et al. Physiologic evaluation of the patient with lung cancer being considered for resectional surgery. Chest 2007; 132: Suppl. 3, 161S-177S.

83 Kelsey CR, Marks LB, Hollis D, et al. Local recurrence after surgery for early stage lung cancer: an 11-year experience with 975 patients. Cancer 2009; 115: 5218-5227.

84 Detterbeck FC, Boffa DJ, Tanoue LT. The new lung cancer staging system. Chest 2009; 136: $260-271$.

85 Pepek JM, Chino JP, Marks LB, et al. How well does the new lung cancer staging system predict for local/regional recurrence after surgery?: a comparison of the TNM 6 and 7 systems. J Thorac Oncol 2011; 6: 757-761.

86 Strand TE, Rostad H, Damhuis RA, et al. Risk factors for 30-day mortality after resection of lung cancer and prediction of their magnitude. Thorax 2007; 62: 991-997.

87 Kozower BD, Sheng S, O’Brien SM, et al. STS database risk models: predictors of mortality and major morbidity for lung cancer resection. Ann Thorac Surg 2010; 90: 875-881.

88 Seely AJ, Ivanovic J, Threader J, et al. Systematic classification of morbidity and mortality after thoracic surgery. Ann Thorac Surg 2010; 90: 936-942.

89 Rueth NM, Parsons HM, Habermann EB, et al. Surgical treatment of lung cancer: predicting postoperative morbidity in the elderly population. J Thorac Cardiovasc Surg 2012; 143: 1314-1323.

90 Rivera C, Falcoz PE, Bernard A, et al. Surgical management and outcomes of elderly patients with early stage nonsmall cell lung cancer: a nested case-control study. Chest 2011; 140: 874-880.

91 Bryant AS, Rudemiller K, Cerfolio RJ. The 30- versus 90-day operative mortality after pulmonary resection. Ann Thorac Surg 2010; 89: 1717-1722.

92 Bernard A, Rivera C, Pages PB, et al. Risk model of in-hospital mortality after pulmonary resection for cancer: a national database of the French Society of Thoracic and Cardiovascular Surgery (Epithor). J Thorac Cardiovasc Surg 2011; 141: 449-458.

93 Ferguson MK, Durkin AE. A comparison of three scoring systems for predicting complications after major lung resection. Eur J Cardiothorac Surg 2003; 23: 35-42.

94 Bradley A, Marshall A, Abdelaziz M, et al. Thoracoscore fails to predict complications following elective lung resection. Eur Respir J 2012; 40: 1496-1501.

95 Möller A, Sartipy U. Predictors of postoperative quality of life after surgery for lung cancer. J Thorac Oncol 2012; 7: 406-411.

96 Ilonen IK, Räsänen JV, Knuuttila A, et al. Quality of life following lobectomy or bilobectomy for non-small cell lung cancer, a two-year prospective follow-up study. Lung Cancer 2010; 70: 347-351.

97 Schulte T, Schniewind B, Dohrmann P, et al. The extent of lung parenchyma resection significantly impacts longterm quality of life in patients with non-small cell lung cancer. Chest 2009; 135: 322-329.

98 Schulte T, Schniewind B, Walter J, et al. Age-related impairment of quality of life after lung resection for non-small cell lung cancer. Lung Cancer 2010; 68: 115-120.

99 Ferguson MK, Parma CM, Celauro AD, et al. Quality of life and mood in older patients after major lung resection. Ann Thorac Surg 2009; 87: 1007-1012.

100 Sarna L, Evangelista L, Tashkin D, et al. Impact of respiratory symptoms and pulmonary function on quality of life of long-term survivors of non-small cell lung cancer. Chest 2004; 125: 439-445.

101 Lüchtenborg M, Jakobsen E, Krasnik M, et al. The effect of comorbidity on stage-specific survival in resected nonsmall cell lung cancer patients. Eur J Cancer 2012; 48: 3386-3395.

102 Hall WH, Ramachandran R, Narayan S, et al. An electronic application for rapidly calculating Charlson comorbidity score. BMC Cancer 2004; 4: 94.

103 Ginsberg RJ, Rubinstein LV. Randomized trial of lobectomy versus limited resection for T1 N0 non-small cell lung cancer. Ann Thorac Surg 1995; 60: 615-622.

104 Hansen HJ, Petersen RH, Christensen M. Video-assisted thoracoscopic surgery (VATS) lobectomy using a standardized anterior approach. Surg Endosc 2011; 25: 1263-1269.

105 Flores RM, Park BJ, Dycoco J, et al. Lobectomy by video-assisted thoracic surgery (VATS) versus thoracotomy for lung cancer. J Thorac Cardiovasc Surg 2009; 138: 11-18.

106 Handy JR Jr, Asaph JW, Douville EC, et al. Does video-assisted thoracoscopic lobectomy for lung cancer provide improved functional outcomes compared with open lobectomy? Eur J Cardiothorac Surg 2010; 37: 451-455.

107 Phillips JD, Merkow RP, Sherman KL, et al. Factors affecting selection of operative approach and subsequent shortterm outcomes after anatomic resection for lung cancer. J Am Coll Surg 2012; 215: 206-215.

108 Swanson SJ, Meyers BF, Gunnarsson CL, et al. Video-assisted thoracoscopic lobectomy is less costly and morbid than open lobectomy: a retrospective multiinstitutional database analysis. Ann Thorac Surg 2012; 93: 1027-1032.

109 Gopaldas RR, Bakaeen FG, Dao TK, et al. Video-assisted thoracoscopic versus open thoracotomy lobectomy in a cohort of 13,619 patients. Ann Thorac Surg 2010; 89: 1563-1570.

110 Ceppa DP, Kosinski AS, Berry MF, et al. Thoracoscopic lobectomy has increasing benefit in patients with poor pulmonary function: a Society of Thoracic Surgeons Database analysis. Ann Surg 2012; 256: 487-493.

111 Nakanishi R, Yamashita T, Oka S. Video-assisted thoracic surgery lobectomy for non-small cell lung cancer in patients with a Charlson comorbidity index score of two or more. J Thorac Oncol 2010; 5: 56-61.

112 Rueth NM, Andrade RS. Is VATS lobectomy better: perioperatively, biologically and oncologically? Ann Thorac Surg 2010; 89: S2107-S2111.

113 Yan TD, Black D, Bannon PG, et al. Systematic review and meta-analysis of randomized and nonrandomized trials on safety and efficacy of video-assisted thoracic surgery lobectomy for early-stage non-small-cell lung cancer. J Clin Oncol 2009; 27: 2553-2562.

114 Flores RM, Ihekweazu UN, Rizk N, et al. Patterns of recurrence and incidence of second primary tumors after lobectomy by means of video-assisted thoracoscopic surgery (VATS) versus thoracotomy for lung cancer. $J$ Thorac Cardiovasc Surg 2011; 141: 59-64. 
115 Carr SR, Schuchert MJ, Pennathur A, et al. Impact of tumor size on outcomes after anatomic lung resection for stage 1A non-small cell lung cancer based on the current staging system. J Thorac Cardiovasc Surg 2012; 143: 390-397.

116 Kilic A, Schuchert MJ, Pettiford BL, et al. Anatomic segmentectomy for stage I non-small cell lung cancer in the elderly. Ann Thorac Surg 2009; 87: 1662-1666.

117 Okada M, Koike T, Higashiyama M, et al. Radical sublobar resection for small-sized non-small cell lung cancer: a multicenter study. J Thorac Cardiovasc Surg 2006; 132: 769-775.

118 Schuchert MJ, Abbas G, Awais O, et al. Anatomic segmentectomy for the solitary pulmonary nodule and early-stage lung cancer. Ann Thorac Surg 2012; 93: 1780-1785.

119 Whitson BA, Groth SS, Andrade RS, et al. Invasive adenocarcinoma with bronchoalveolar features: a populationbased evaluation of the extent of resection in bronchoalveolar cell carcinoma. J Thorac Cardiovasc Surg 2012; 143: 591-600.

120 Watanabe S, Watanabe T, Arai K, et al. Results of wedge resection for focal bronchioloalveolar carcinoma showing pure ground-glass attenuation on computed tomography. Ann Thorac Surg 2002; 73: 1071-1075.

121 Kim HK, Choi YS, Kim J, et al. Management of multiple pure ground-glass opacity lesions in patients with bronchioloalveolar carcinoma. J Thorac Oncol 2010; 5: 206-210.

122 Nakao M, Yoshida J, Goto K, et al. Long-term outcomes of 50 cases of limited-resection trial for pulmonary ground-glass opacity nodules. J Thorac Oncol 2012; 7: 1563-1566.

123 Schuchert MJ, Kilic A, Pennathur A, et al. Oncologic outcomes after surgical resection of subcentimeter non-small cell lung cancer. Ann Thorac Surg 2011; 91: 1681-1687.

124 Kates M, Swanson S, Wisnivesky JP. Survival following lobectomy and limited resection for the treatment of stage I non-small cell lung cancer $\leqslant 1 \mathrm{~cm}$ in size: a review of SEER data. Chest 2011; 139: 491-496.

125 Whitson BA, Groth SS, Andrade RS, et al. Survival after lobectomy versus segmentectomy for stage I non-small cell lung cancer: a population-based analysis. Ann Thorac Surg 2011; 92: 1943-1950.

126 Billmeier SE, Ayanian JZ, Zaslavsky AM, et al. Predictors and outcomes of limited resection for early-stage nonsmall cell lung cancer. J Natl Cancer Inst 2011; 103: 1621-1629.

127 Nomori H, Mori T, Ikeda K, et al. Segmentectomy for selected cT1N0M0 non-small cell lung cancer: a prospective study at a single institute. J Thorac Cardiovasc Surg 2012; 144: 87-93.

128 Koike T, Koike T, Yamato Y, et al. Prognostic predictors in non-small cell lung cancer patients undergoing intentional segmentectomy. Ann Thorac Surg 2012; 93: 1788-1794.

129 Allen MS, Darling GE, Pechet TT, et al. Morbidity and mortality of major pulmonary resections in patients with early-stage lung cancer: initial results of the randomized, prospective ACOSOG Z0030 trial. Ann Thorac Surg 2006; 81: 1013-1019.

130 Van Schil PE, Asamura H, Rusch VW, et al. Surgical implications of the new IASLC/ATS/ERS adenocarcinoma classification. Eur Respir J 2012; 39: 478-486.

131 Kim HK, Choi YS, Kim K, et al. Management of ground-glass opacity lesions detected in patients with otherwise operable non-small cell lung cancer. J Thorac Oncol 2009; 4: 1242-1246.

132 Nakamura K, Saji H, Nakajima R, et al. A phase III randomized trial of lobectomy versus limited resection for smallsized peripheral non-small cell lung cancer (JCOG0802/WJOG4607L). Jpn J Clin Oncol 2010; 40: 271-274.

133 National Cancer I. Phase III Randomized Study of Lobectomy Versus Sublobar Resection in Patients With Small Peripheral Stage IA Non-Small Cell Lung Cancer. CALGB-140503. www.calgb.org/Public/meetings/presentations/ 2007/cra_ws/03-140501-Altorki062007.pdf Date last accessed October 7, 2013.

134 Palma D, Visser O, Lagerwaard FJ, et al. Treatment of stage I NSCLC in elderly patients: a population-based matched-pair comparison of stereotactic radiotherapy versus surgery. Radiother Oncol 2011; 101: 240-244.

135 Onishi H, Shirato H, Nagata Y, et al. Stereotactic body radiotherapy (SBRT) for operable stage I non-small-cell lung cancer: can SBRT be comparable to surgery? Int J Radiat Oncol Biol Phys 2011; 81: 1352-1358.

136 Matsuo Y, Shibuya K, Nagata Y, et al. Preliminary report of late recurrences, at 5 years or more, after stereotactic body radiation therapy for non-small cell lung cancer. J Thorac Oncol 2012; 7: 453-456.

137 Corradetti MN, Haas AR, Rengan R. Central-airway necrosis after stereotactic body-radiation therapy. $N$ Engl J Med 2012; 366: 2327-2329.

138 Rowe BP, Boffa DJ, Wilson LD, et al. Stereotactic body radiotherapy for central lung tumors. J Thorac Oncol 2012; 7: 1394-1399.

139 Mayo Clinic Clinical T. Stereotactic Body Radiotherapy (SBRT) versus Sublobar Resection for High-Risk Patients with Early Stage Non-Small Lung Cancer (NSCLC). http://clinicaltrials.gov/ct2/show/NCT01622621?term= stereotactic+body+radiotherapy+versus+sublobar+resections\&rank $=1$ Date last accessed: October 7, 2013. Date last updated: January 17, 2013.

140 Center MDAC. Randomized Study to Compare CyberKnife to Surgical Resection in Stage I Non-small Cell Lung Cancer (STARS). http://clinicaltrials.gov/ct2/show/NCT00840749?term =cyberknife+STARS\&rank=1 Date last accessed: October 7, 2013. Date last updated: April 5, 2013.

141 Dupuy DE. Image-guided thermal ablation of lung malignancies. Radiology 2011; 260: 633-655.

142 Lanuti M, Sharma A, Willers H, et al. Radiofrequency ablation for stage I non-small cell lung cancer: management of locoregional recurrence. Ann Thorac Surg 2012; 93: 921-927.

143 Tada A, Hiraki T, Iguchi T, et al. Influence of radiofrequency ablation of lung cancer on pulmonary function. Cardiovasc Intervent Radiol 2012; 35: 860-867.

144 Ambrogi MC, Fanucchi O, Cioni R, et al. Long-term results of radiofrequency ablation treatment of stage I nonsmall cell lung cancer: a prospective intention-to-treat study. J Thorac Oncol 2011; 6: 2044-2051.

145 Kashima M, Yamakado K, Takaki H, et al. Complications after 1000 lung radiofrequency ablation sessions in 420 patients: a single center's experiences. AJR Am J Roentgenol 2011; 197: W576-W580.

146 Simon CJ, Dupuy DE, DiPetrillo TA, et al. Pulmonary radiofrequency ablation: long-term safety and efficacy in 153 patients. Radiology 2007; 243: 268-275.

147 Bilal H, Mahmood S, Rajashanker B, et al. Is radiofrequency ablation more effective than stereotactic ablative radiotherapy in patients with early stage medically inoperable non-small cell lung cancer? Interact Cardiovasc Thorac Surg 2012; 15: 258-265. 
148 Strohschein FJ, Bergman H, Carnevale FA, et al. Patient decision making among older individuals with cancer. Qual Health Res 2011; 21: 900-926.

149 Yellen SB, Cella DF. Someone to live for: social well-being, parenthood status, and decision-making in oncology. J Clin Oncol 1995; 13: 1255-1264.

150 Elkin EB, Kim SH, Casper ES, et al. Desire for information and involvement in treatment decisions: elderly cancer patients' preferences and their physicians' perceptions. J Clin Oncol 2007; 25: 5275-5280.

151 Hillerdal G. Indolent lung cancers - time for a paradigm shift: a review. J Thorac Oncol 2008; 3: 208-211.

152 Jaklitsch MT, Jacobson FL, Austin JH, et al. The American Association for Thoracic Surgery guidelines for lung cancer screening using low-dose computed tomography scans for lung cancer survivors and other high-risk groups. J Thorac Cardiovasc Surg 2012; 144: 33-38.

153 Nicholas J. Harmonizing lung cancer screening guidelines. J Natl Cancer Inst 2012; 104: 1531-1532. 